\title{
A Study of Pitch Oscillation and Roughness on Airfoils Used for Horizontal Axis Wind Turbines
}

G. M. Gregorek

M. J. Hoffmann

R. R. Ramsay

J. M. Janiszewska

The Ohio State University

Columbus, Ohio

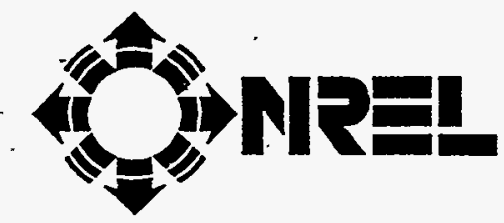

MASTER

National Renewable Energy Laboratory 1617 Cole Boulevard

Golden, Colorado 80401-3393

A national laboratory of the U.S. Department of Energy Managed by Midwest Research Institute for the U.S. Department of Energy

under Contract No. DE-AC36-83CH10093 


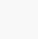




\section{A Study of Pitch Oscillation and Roughness on Airfoils Used for Horizontal Axis Wind Turbines}

G. M. Gregorek

M. J. Hoffmann

R. R. Ramsay

J. M. Janiszewska

The Ohio State University

Columbus, Ohio

NREL Technical Monitor:

C. P. Butterfield

\section{MNRE MASTER}

National Renewable Energy Laboratory 1617 Cole Boulevard

Golden, Colorado 80401-3393

A national laboratory of the U.S. Department of Energy Managed by Midwest Research Institute for the U.S. Department of Energy under contract No. DE-AC36-83CH10093

Prepared under Subcontract No. XF-1-11009-3

December 1995 


\section{NOTICE}

This report was prepared as an account of work sponsored by an agency of the United States government. Neither the United States government nor any agency thereof, nor any of their employees, makes any warranty, express or implied, or assumes any legal liability or responsibility for the accuracy, completeness, or usefulness of any information, apparatus, product, or process disclosed, or represents that its use would not infringe privately owned rights. Reference herein to any specific commercial product, process, or service by trade name, trademark, manufacturer, or otherwise does not necessarily constitute or imply its endorsement, recommendation, or favoring by the United States govemment or any agency thereof. The views and opinions of authors expressed herein do not necessarily state or reflect those of the United States government or any agency thereof.

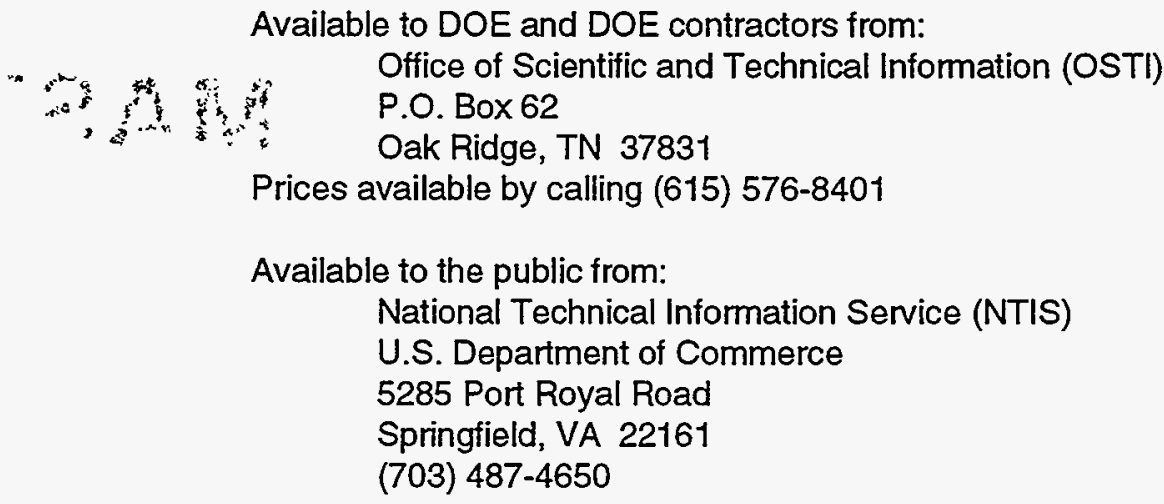

Available to DOE and DOE contractors from: 


\section{Foreword}

Airfoils for wind turbines have been selected by comparing data from different wind tunnels, tested under different conditions, making it difficult to make accurate comparisons. Most wind tunnel data sets do not contain airfoil performance in stall commonly experienced by turbines operating in the field. Wind turbines commonly experience extreme roughness for which there is very little data. Finally, recent tests have shown that dynamic stall is a common occurrence for most wind turbines operating in yawed, stall or turbulent conditions. Very little dynamic stall data exists for the airfoils of interest to a wind turbine designer. In summary, very little airfoil performance data exists which is appropriate for wind turbine design.

Recognizing the need for a wind turbine airfoil performance data base, the National Renewable Energy Laboratory (NREL), funded by the U.S. Department of Energy, awarded a contract to Ohio State University (OSU) to conduct a wind tunnel test program. Under this program, OSU tested a series of popular wind turbine airfoils. A standard test matrix was developed to assure that each airfoil was tested under the same conditions. The test matrix was developed in partnership with industry and is intended to include all of the operating conditions experienced by wind turbines. These conditions include airfoil performance at high angles of attack, rough leading edge (bug simulation), steady and unsteady angles of attack.

Special care has been taken to report as much of the test conditions and raw data as practical so that designers can make their own comparisons and focus on details of the data relevant to their design goals. Some of the airfoil coordinates are proprietary to NREL or an industry partner. To protect the information which defines the exact shape of the airfoil, the coordinates have not been included in the report. Instructions on how to obtain these coordinates may be obtained by contacting C.P. (Sandy) Butterfield at NREL.

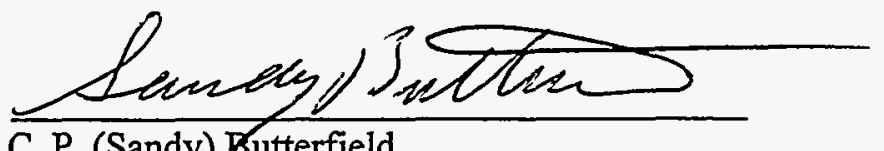

C. P. (Sandy) Butterfield

Wind Technology Division

National Renewable Energy Laboratory

1617 Cole Boulevard

Golden, Colorado 80401 USA

Internet Address: Sandy_Butterfield@NREL.GOV

Phone: 303-384-6902

FAX: $303-384-6901$ 


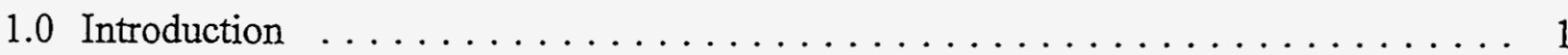

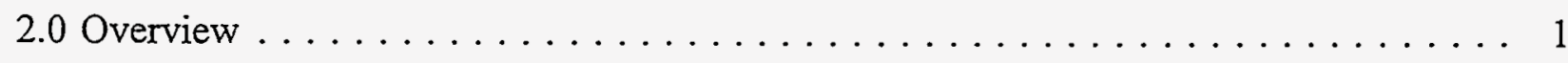

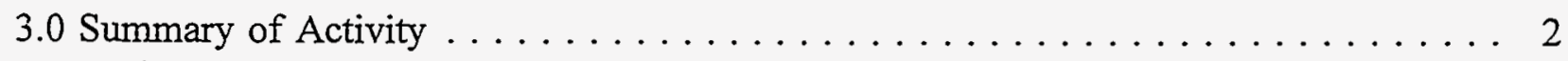

$3.13 \times 5$ Wind Tunnel Airfoil Model Testing ................ 2

3.1 .1 Model Detail . . . . . . . . . . . . . . . . . 2

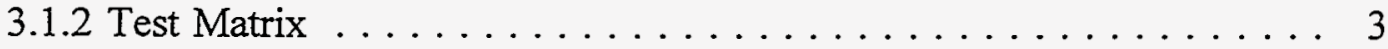

3.1 .3 Steady State Data ....................... 3

3.1 .4 Unsteady Characteristics . . . . . . . . . . . . . . . . . 6

$3.26 \times 12$ Wind Tunnel Model Testing ..................... . . 9

3.3 Project Improvements . . . . . . . . . . . . . . . . . . . . . . . 9

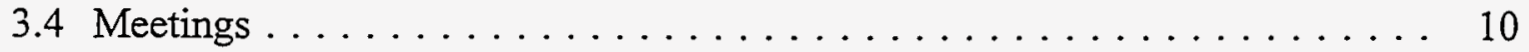

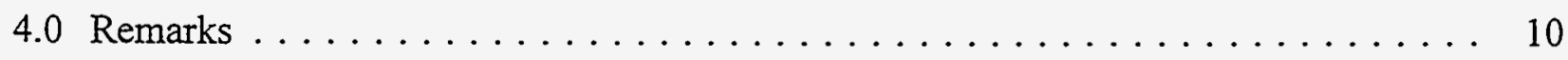

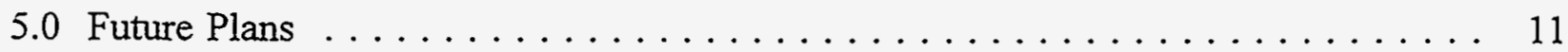




\section{List of Figures}

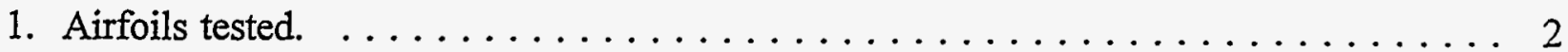

2. Difference Plot. ............................ 3

3. Theory comparison for $\operatorname{LS}(1)-0421 \mathrm{MOD} . \ldots \ldots \ldots \ldots \ldots \ldots \ldots \ldots \ldots$

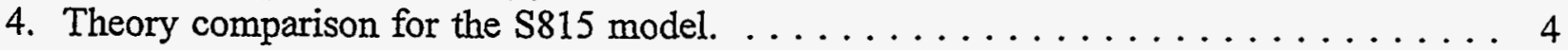

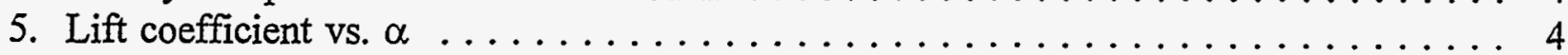

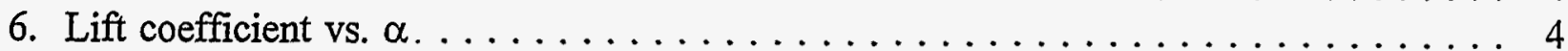

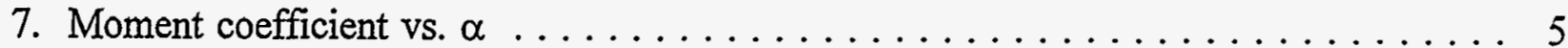

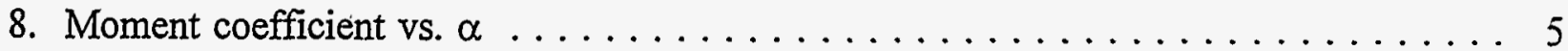

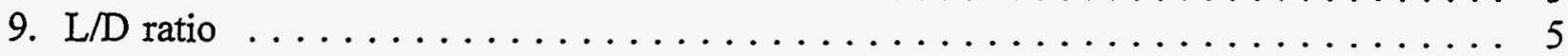

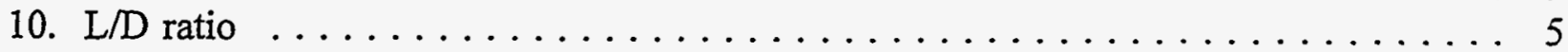

11. Unsteady pressure surface plot. $\ldots \ldots \ldots \ldots \ldots \ldots \ldots \ldots \ldots \ldots \ldots \ldots \ldots \ldots$

12. S801, dynamic lift, clean ........................ 7

13. S801, dynamic moment, clean . . . . . . . . . . . . . . . 7

14. Dynamic lift, clean ........................ 7

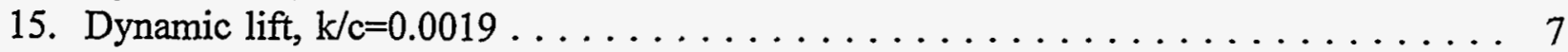

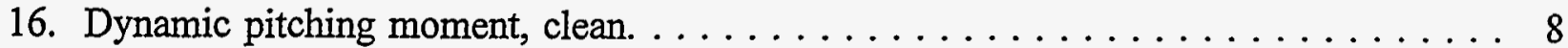

17. Dynamic moment, $\mathrm{k} / \mathrm{c}=0.0019 \ldots \ldots \ldots \ldots \ldots \ldots \ldots \ldots \ldots \ldots$. . . . . . . . . . . 8

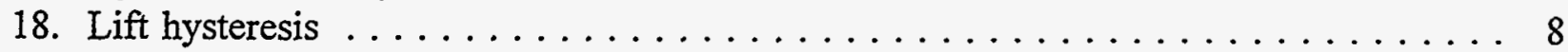

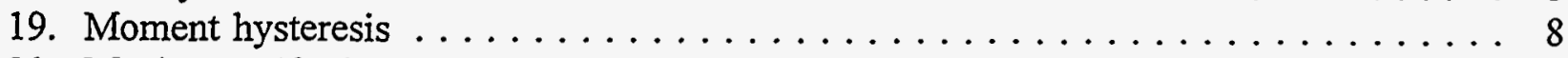

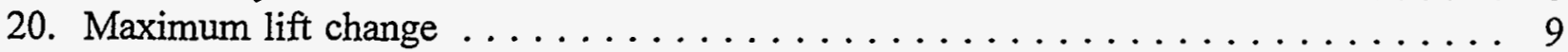

21. Moment change at maximum lift $\ldots \ldots \ldots \ldots \ldots \ldots \ldots \ldots \ldots$ 



\subsection{Introduction}

Under Subcontract XF-1-11009-3 the Ohio State University Aeronautical and Astronautical Research Laboratory (OSU/AARL) with the National Renewable Energy Laboratory (NREL) developed an extensive database of empirical aerodynamic data. These data will assist in the development of analytical models and in the design of new airfoils for wind turbines. To accomplish the main objective, airfoil models were designed, built and wind tunnel tested with and without model leading edge grit roughness (LEGR). LEGR simulates surface irregularities due to the accumulation of insect debris, ice, and/or the aging process. This report is a summary of project activity for Phase III, which encompasses, the time period from September 17, 1993 to September 16, 1994.

\subsection{Overview}

Several major activities occurred during Phase III of this project, include the following:

-model designing, procuring and verifying

-improving model geometry verification techniques and report generation methods

-model testing in the $3 \times 5$ Subsonic Wind Tunnel (3x5)

-conducting limited tests in the $6 \times 12$ Blowdown Wind Tunnel

-attending and participating in national and NREL meetings.

During Phase III, six airfoil models were tested in the OSU/AARL. Although the LS(1)-0421MOD airfoil model was purchased under Phase II, this model was received at the beginning of Phase III and tested from October to December 1993. Subsequently, the data report for this airfoil was submitted in February 1994. The next airfoil tested was the NACA 4415. This was a repeat test conducted to give consistency to all the data taken in the $3 \times 5$. After the original tests of this model, during Phase II, the $3 \times 5$ wind tunnel was recalibrated and the face cams that produce the pitch oscillations were redesigned and replaced. This testing was completed in January 1994 and the report was submitted in May 1994. The S809 airfoil model, which was ordered and built during Phase III, was tested in March 1994; the report was submitted in June 1994. The next airfoil, the S801, was provided by KENETECH, Windpower Inc. The model was tested in April 1994 and the data report was supplied in July 1994. After the completion of these tests, a repeat test was conducted on the LS(1)-0417MOD airfoil model, again, to provide a consistent database. The testing period was during May 1994 and this data report was also submitted in July 1994. The final Phase III test was the of S815 airfoil model in July 1994. The data report for this test was delivered in August 1994.

In addition to the airfoils tested completely during Phase III, the S810 model was ordered, and received, and will be tested in early Phase IV. Also, the S814 airfoil coordinates and tap locations were prepared so they can be sent to the manufacturer when required.

The model contour measurements and validation were incorporated into the model reparation procedures and check lists for the model test sequence were developed. Programs were written 
or improved to allow for easier data plotting and document generation.

The OSU/AARL 6x12 Blowdown Wind Tunnel was used for a limited number of tests to determine the feasibility of using this wind tunnel to study some higher Reynolds number data that are out of range of the $3 \times 5$ wind tunnel. The main purpose of these tests was to determine if the facility could provide suitable flow quality at low Mach number and higher Reynolds number which is desired for large-wind-turbine airfoil testing.

Finally, OSU/AARL staff participated in the NREL Contractor Review meeting in October 1994 and the ASME/ETCE Wind Energy Conference in New Orleans. Finally, OSU/AARL staff attended the AWEA/Windpower at Minneapolis in May 1994, and gave a presentation on the unsteady characteristics of some of the tested airfoil models.

\subsection{Summary of Activity}

\subsection{3x5 Wind Tunnel Airfoil Model Testing}

Most of Phase III was dedicated to developing and testing airfoils in the $3 \times 5$ wind tunnel. The following three sections outline the issues and summarize results of these tests. This report is not intended to be all-inclusive, but a summary of the results from Phase III. Therefore, to keep this document concise, not all data discussed are shown in graphical form. Data reports for all six of the airfoil models tested in phase III have been submitted to NREL for publication.

\subsubsection{Model Detail}

Figure 1 depicts the airfoils tested in phase III: LS(1)-0421MOD, NACA 4415, LS(1)-0417MOD, $\mathrm{S} 809, \mathrm{~S} 801, \mathrm{~S} 815$. Before each model was placed in the $3 \times 5$ wind tunnel, the contour was
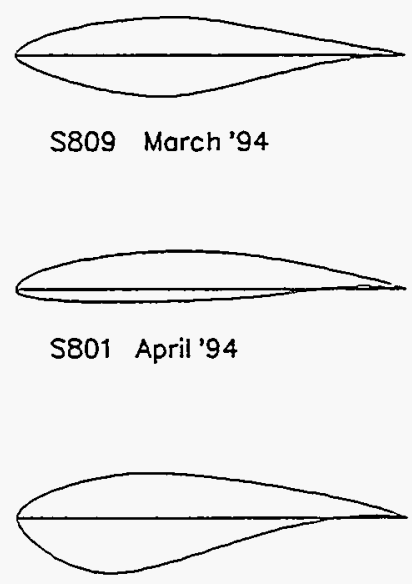

S815 June'94

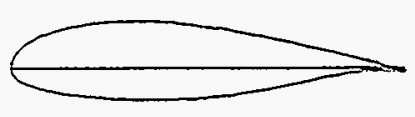

LS(1)-0421MOD October'93
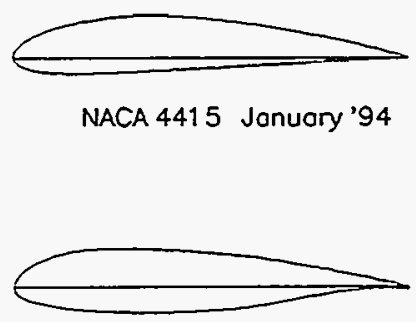

LS(1)-0417MOD May '94

Figure 1. Airfoils tested. 
measured on a Sheffield-Cordax Coordinate Measuring Machine (CMM) at three spanwise locations. Each location was then compared to a set of desired coordinates in order to determine if the model was delivered within the desired tolerance. A computer program was developed to make these comparisons.

Figure 2 is a representative difference plot showing the accuracy of the S801 model. The high deviations around the trailing edge are due to the use of a desired-coordinate file with a sharp trailing edge for comparison. Since, the model trailing edge was thickened for manufacturing purposes, this "deviation" was accepted. Measuring and comparing process showed the S815 airfoil model not within required tolerance, and it was returned to the manufacturer for correction. The model was reworked until the surface around the middle span was determined to be acceptable.

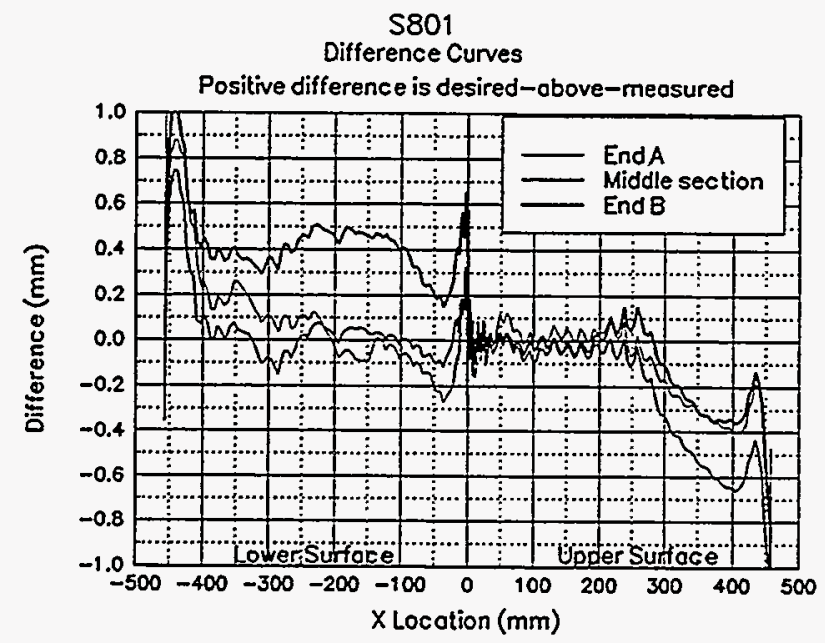

Figure 2. Difference plot.

\subsubsection{Test Matrix}

For each model, steady state and pitch oscillation data were taken for both clean and LEGR. The matrix for the steady state tests was Reynolds numbers of $0.75,1.0,1.25$ and 1.4 or 1.5 million and angles of attack from $-20^{\circ}$ or $-10^{\circ}$ to $+40^{\circ}$. Pitch oscillation data were taken at the same Reynolds numbers as the steady state data for three mean angles of attack, $8^{\circ}, 14^{\circ}$, and $20^{\circ}$, and three frequencies, $0.6,1.2$ and $1.8 \mathrm{~Hz}$. Two face cams were used to produce two different amplitude sine wave forcing functions of $\pm 5.5^{\circ}$ and $\pm 10^{\circ}$. Although the LS(1)-0421MOD airfoil was tested at all of the above steady state and oscillating conditions, only $0.75,1.0$, and 1.25 million Reynolds numbers were used for the steady state tests.

\subsubsection{Steady State Data}

To check the accuracy of the data taken for each model, the data were compared with the analytical lift and moment coefficients from the North Carolina State airfoil analysis code. 
Figures 3 and 4 represent the lift and moment coefficients for the LS(1)-0421MOD and the S815 airfoils in comparison with theoretical values for the 1.25 million Reynolds number case. For both airfoils, it is apparent that the lift and the moment coefficient data are in reasonable agreement with theoretical calculations at moderately low angles of attack. Although not shown, analytical pressure distributions for $0^{\circ}$ to $6^{\circ}$ angles of attack were also compared to experimental data and showed correspondingly good agreement.

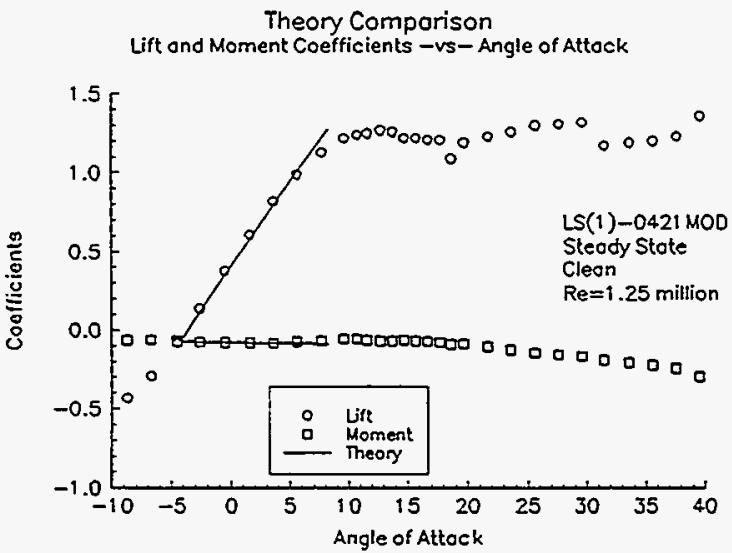

Figure 3. Theory comparison for LS(1)-0421MOD.

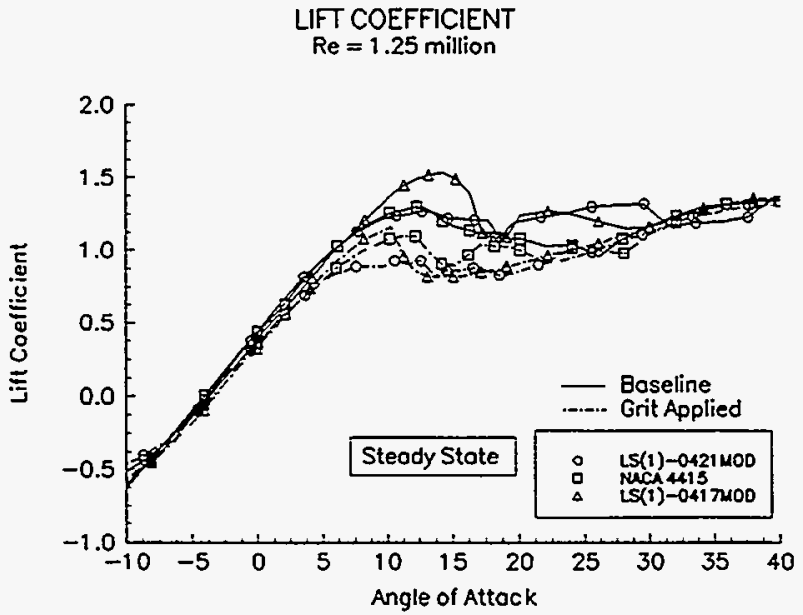

Figure 5. Lift coefficient vs. $a$.

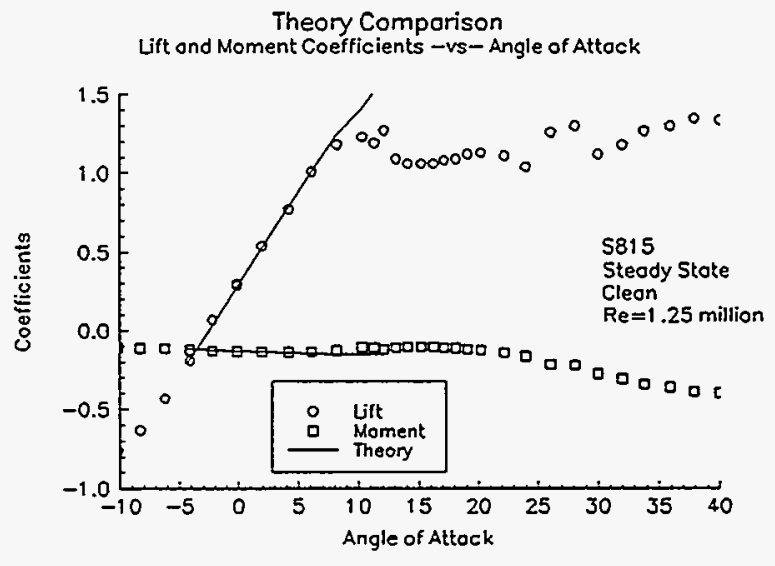

Figure 4. Theory comparison for the $\$ 815$ model.

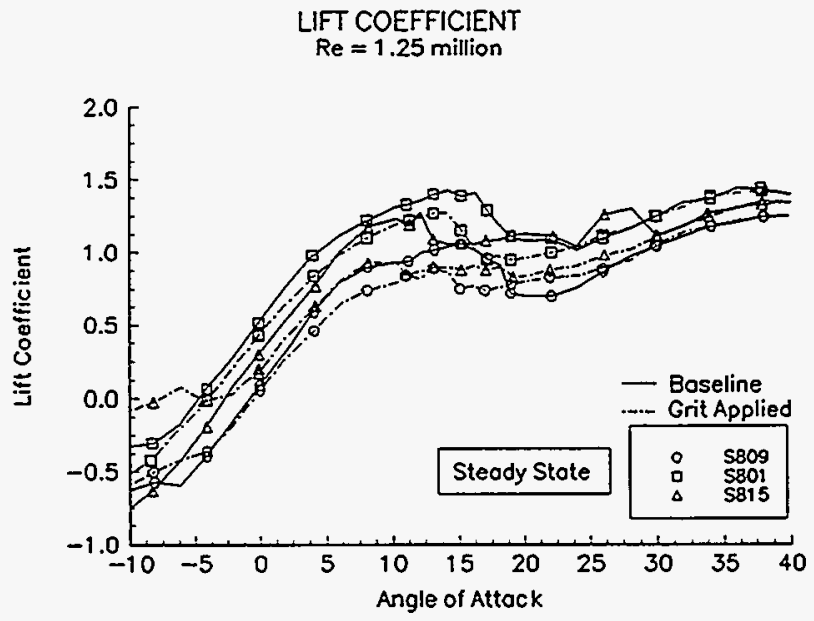

Figure 6. Lift coefficient vs. $a$.

Both clean and LEGR lift coefficient steady state cases are plotted in Figures 5 and 6 for all six airfoils tested during Phase III. Although the requirements of a particular wind turbine will govern which airfoil is best suited, changes in performance that come about with the application of LEGR should be considered when choosing airfoils for wind turbine applications. The reduction in steady state maximum lift coefficient for the LEGR versus clean cases ranges from $12 \%$ for the S801 to nearly $28 \%$ for the S 815 and both LS(1) series airfoil models. The 
application of LEGR also moves the airfoil stall to slightly lower angles of attack.

As would be expected, minimum drag is affected by the application of LEGR. In the cases of the NACA 4415, LS(1)-0417MOD, S801, and S815, the minimum drag is increased by up to $50 \%$; the LS(1)-0421MOD and S809 airfoil models can have LEGR drag almost double that of the clean case. Figures 7 and 8 show the corresponding quarter chord pitching moment coefficients. The application of LEGR has the strongest effect on the magnitude of the pitching moment at zero lift on the $\mathrm{S} 815$ airfoil model, reducing it by $70 \%$. This model showed a very early negative stall when LEGR was applied, which affected the zero lift pitching moment significantly. Other models showed a reduction in the magnitude of the zero lift pitching moment ranging from $7 \%$ for the $\mathrm{S} 801$ to $27 \%$ for the S809. Steady state data indicates that the S801 model is the least affected by the application of LEGR, whereas the S815 or the LS(1)-0421MOD most affected.

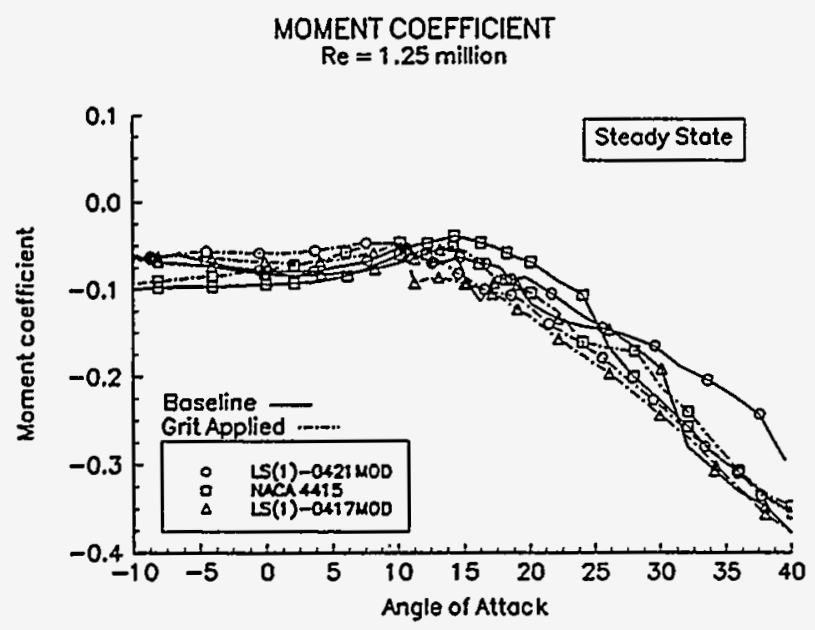

Figure 7. Moment coefficient vs. $a$.

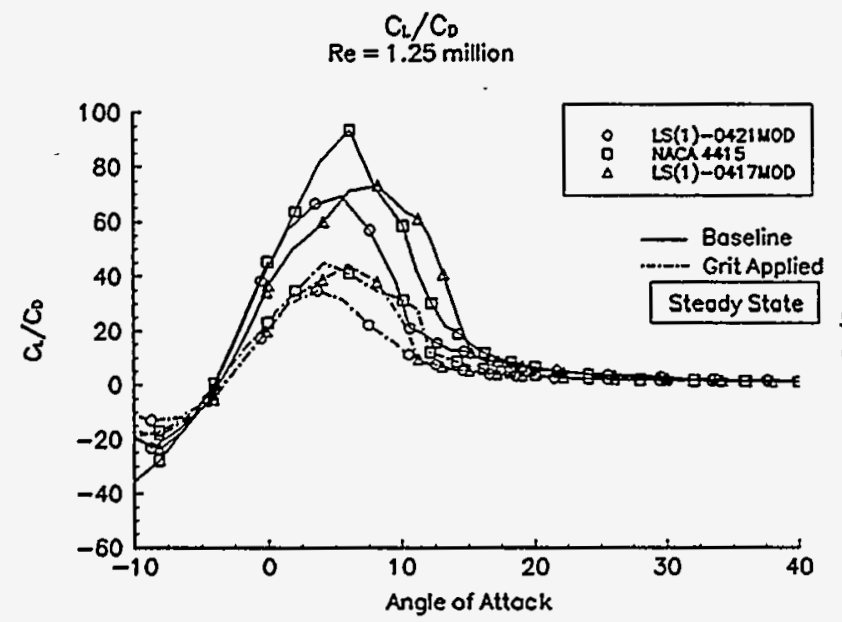

Figure 9. L/D ratio.

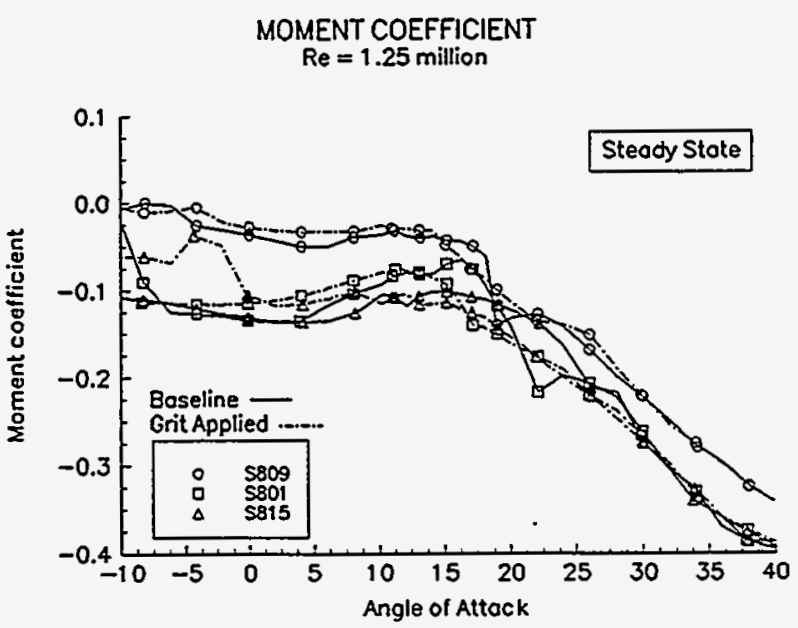

Figure 8. Moment coefficient vs. $a$.

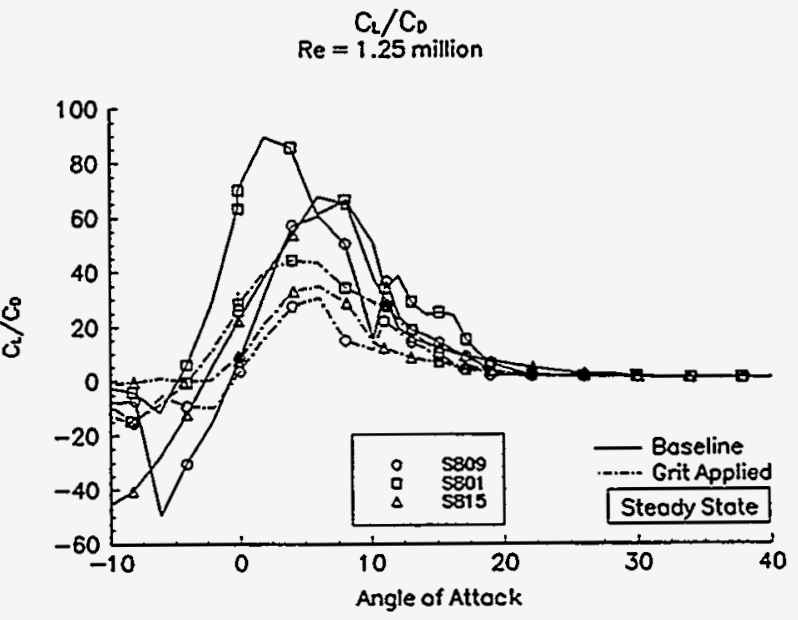

Figure 10. L/D ratio. 
As shown in Figures 9 and 10, the application of LEGR reduced the lift-to-drag (L/D) ratio by approximately $50 \%$ in some cases. Also a tendency to move the maximum $\mathrm{L} / \mathrm{D}$ to a lower angle of attack with the application of grit is apparent, especially for the LS(1) series of airfoils.

\subsubsection{Unsteady Characteristics}

The pitch oscillation data were taken at the same Reynolds numbers as the steady state data, both clean and with LEGR. Two oscillation amplitudes of $\pm 5.5^{\circ}$ and $\pm 10^{\circ}$ were used at $0.6,1.2$, and $1.8 \mathrm{~Hz}$ frequencies and with $8^{\circ}, 14^{\circ}$, and $20^{\circ}$ mean angles of attack. Figure 11 shows a sample pressure coefficient surface plot obtained for the S815 airfoil model at 1.22 million Reynolds number, $1.21 \mathrm{~Hz}$, and $14^{\circ} \pm 10^{\circ}$ angle of attack. The $\mathrm{S} 815$ unsteady pressure distribution shows that part of the flow on the upper surface is separated and peak pressure coefficients are approximately -3.5 . The pressure coefficients used for these surface plots were curve fit to obtain an equally spaced grid for plotting purposes. This was a change implemented in 1994 that gave a more accurate representation and timely production of this type of plot.

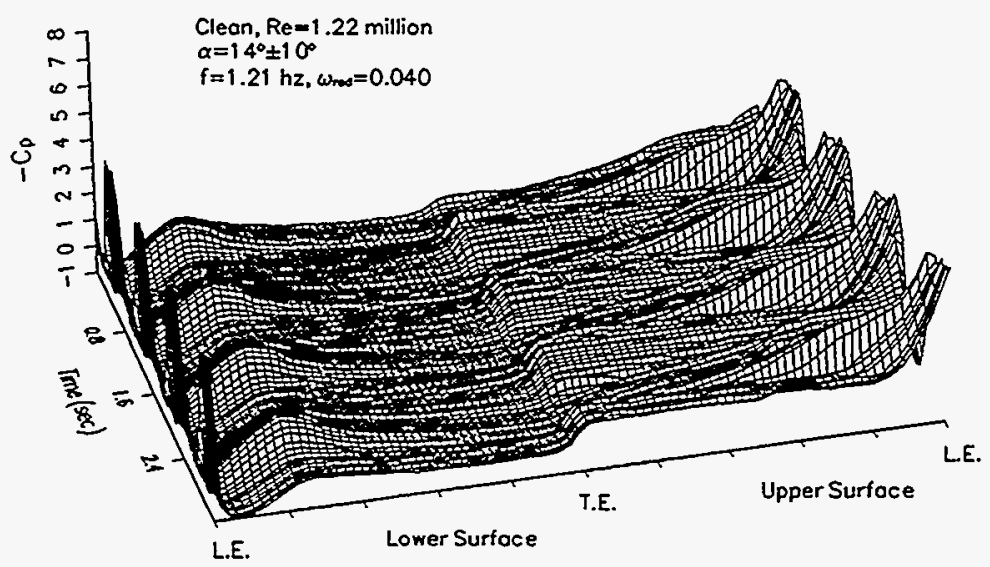

Figure 11. Unsteady pressure surface plot.

From the acquired pressure data, the coefficients of lift, quarter chord pitching moment, and pressure drag can be integrated. Figures 12 and 13 show examples of lift and pitching moment coefficient data. These are "scatter" plots of the data shown with three mean angles of attack for the $\pm 10^{\circ}$ amplitude case on one plot. At the higher angles of attack the scatter became more apparent; therefore, the $8^{\circ}$ or $14^{\circ}$ mean angles gave the best results when a curve fit of the data was desired. In order to make some comparisons between the oscillating test data for each airfoil, plots were generated using a polynomial curve fit to smooth out the data. Figures 14 and 15 show the dynamic lift plots for the S series models clean and LEGRcases, respectively. The unsteady oscillation of the model produced lift up to $85 \%$ higher for the S809 clean case and $103 \%$ higher for the S815 LEGR case compared to the steady state values while the models are traveling with increasing angle of attack. As in steady state cases LEGR reduced the maximum unsteady lift coefficient. Although the data are not shown here due to limited space, the $\pm 5.5^{\circ}$ amplitude oscillation generally showed a higher percentage of lift reduction with LEGR applied than did the larger $\pm 10^{\circ}$ oscillations. The maximum reduction in lift from LEGR occurred on 


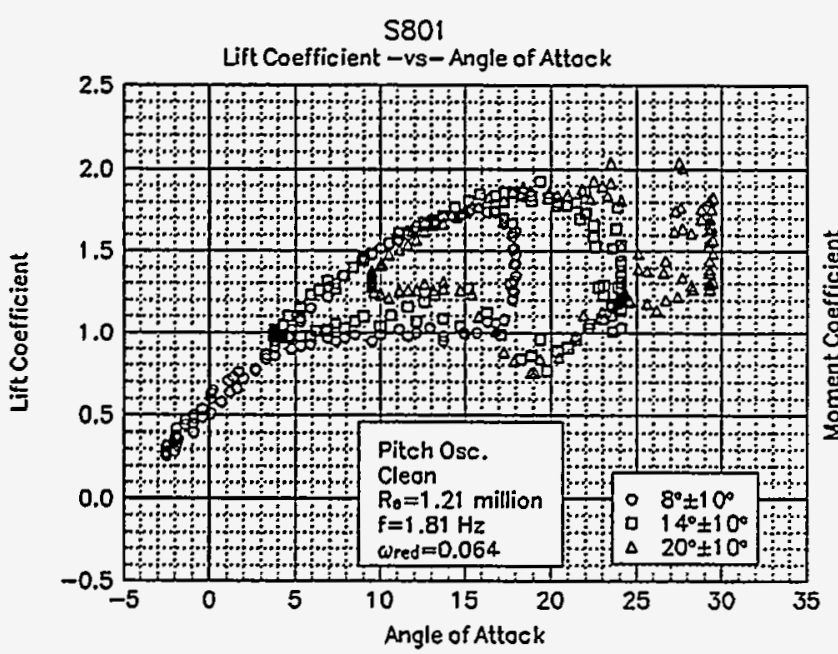

Figure 12. $\$ 801$, dynamic lift, clean.

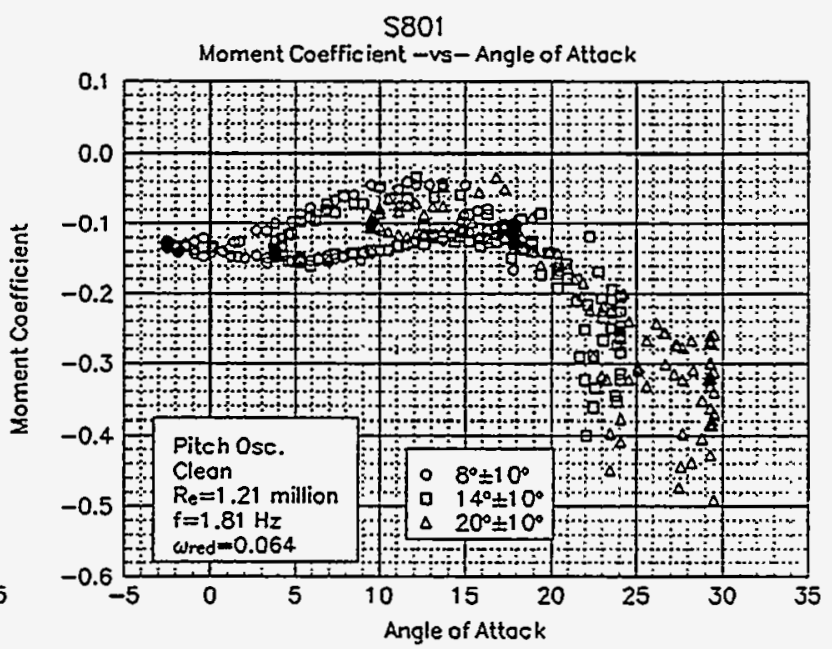

Figure 13. S801, dynamic moment, clean.

the LS(1)-0417MOD airfoil model with a $25 \%$ reduction and the least effect occurred on the S801, which had a $4 \%$ reduction in lift. Overall, the effect of LEGR on unsteady lift data was less severe than on the steady state lift data. Figures 14 and 15 also show that the application of LEGR reduced the recovery when the model was traveling with decreasing angle of attack (shown as a "flatter" section on the lower portion of the curves).

DYNAMIC LIFT

$R e=1,25$ Million, $f=1.8 \mathrm{~Hz}, \pm 10^{\circ}$ Com, $\omega_{r e s}=0.062$

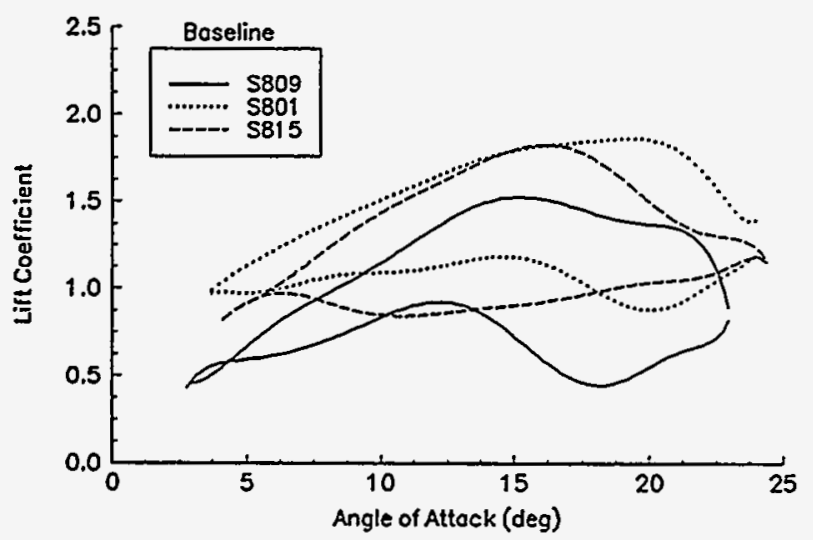

Figure 14. Dynamic lift, clean.
DYNAMIC LIFT

$R e=1.25$ Million, $f=1.8 \mathrm{~Hz} . \pm 10^{\circ} \mathrm{Com}, \omega_{\text {res }}=0.062$

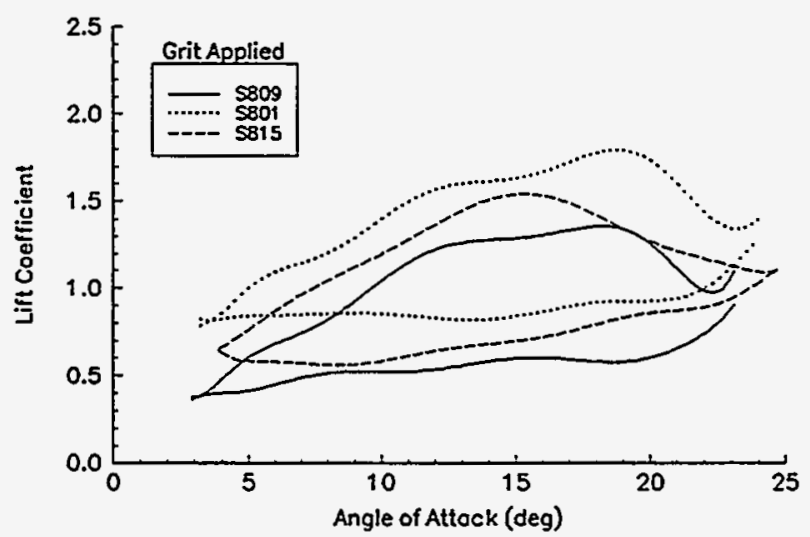

Figure 15. Dynamic lift, $\mathrm{k} / \mathrm{c}=0.0019$.

The dynamic pitching moment is represented in Figures 16 and 17 for the LS(1) series and the NACA airfoils. These figures show a hysteresis behavior due to pitch oscillation that was apparent in all the airfoil models tested. The application of LEGR had a drastic effect on the LS(1)-0417MOD airfoil. There was quite a lot of scatter in the original data, which made it more difficult to curve fit; therefore, there is notable fluctuation in the curve fit. The moment created was approximately seven times greater than the steady state values at the same high angles of attack. In general, however, LEGR application caused a decrease in the magnitude of the unsteady quarter chord pitching moment for the airfoils tested at moderate angles of attack, i.e., less than $15^{\circ}$. 
DYNAMIC PITCHING MOMENT $R e=1.25$ Million, $f=1.8 \mathrm{~Hz}, \pm 10 \mathrm{Cam}$, wred $=0.068$

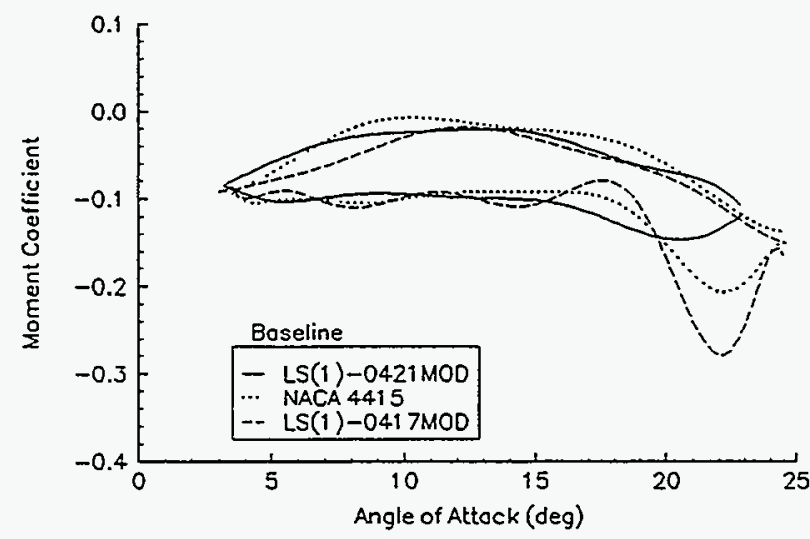

Figure 16. Dynamic pitching moment, clean.

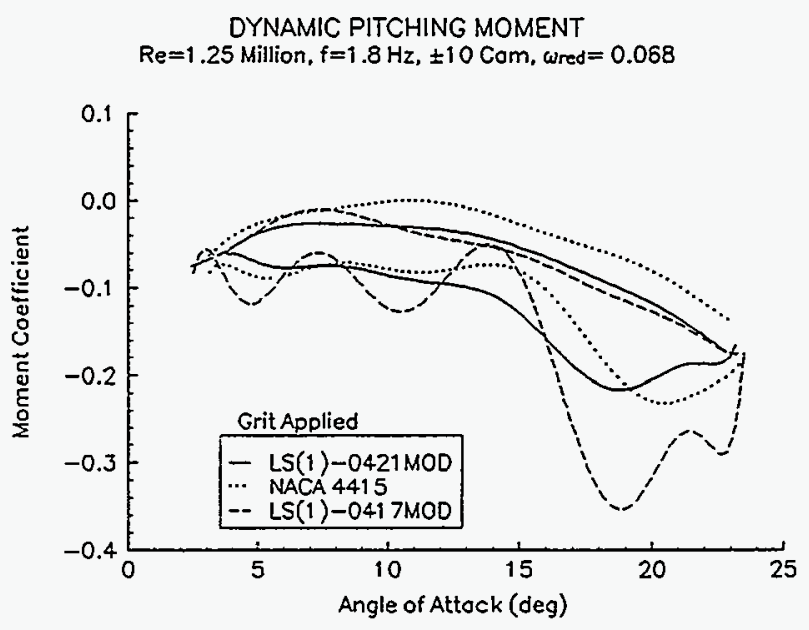

Figure 17. Dynamic moment, $k / c=0.0019$.

As described earlier, the pitch oscillation data showed a hysteresis effect that depended on increasing or decreasing angle of attack. In order to quantify this effect, lift and moment hysteresis variables were developed. These represent the size of the hysteresis loop by taking the difference between the increasing lift/moment and decreasing lift/moment as the airfoil oscillating through the sinusoidal angle of attack wave. Figures 18 and 19 show the lift and moment

LIFT HYSTERESIS
Re $=1.25$ Million

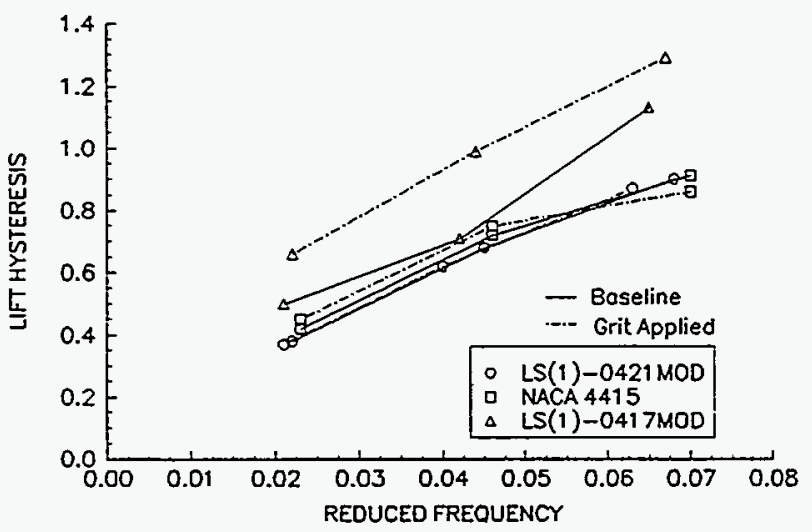

Figure 18. Lift hysteresis.
MOMENT HYSTERESIS

$\operatorname{Re}=1.25$ Million

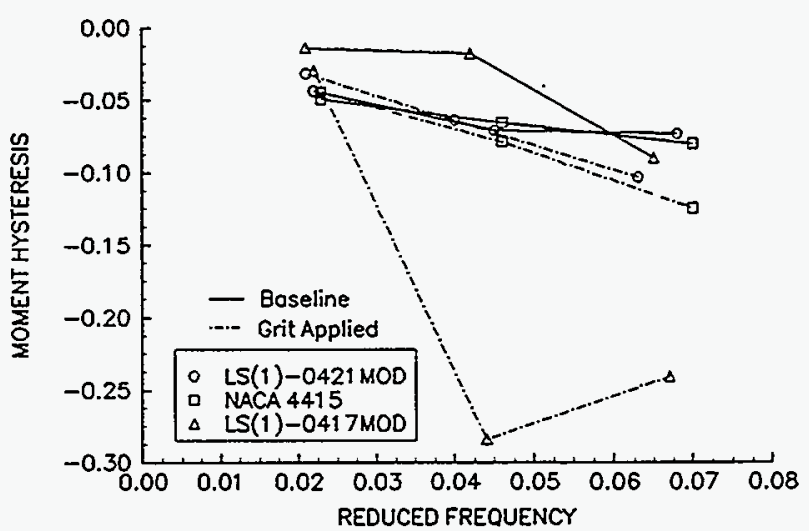

Figure 19. Moment hysteresis.

hysteresis for the LS(1) series and the NACA airfoils. Even for airfoils not shown in these figures, lift and pitching moment hysteresis becomes more apparent with increased reduced frequency. (The reduced frequency is a function of the frequency, chord length and air speed.) In comparing the clean and LEGR cases, the LS(1)-0417MOD experienced the greatest hysteresis changes in both lift and moment, again indicating that the LEGR effect was very different for this model.

Figures 20 and 21 represent the effect of LEGR on pitch oscillation in compared to the steady state data for the $\mathrm{S}$ series of airfoil models. Lift change is calculated by finding the percent 


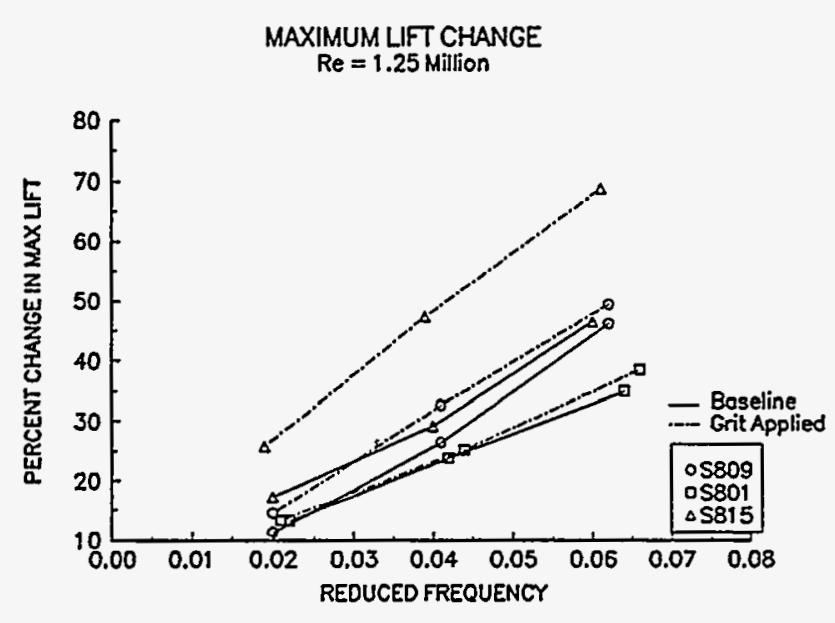

Figure 20. Maximum lift change.

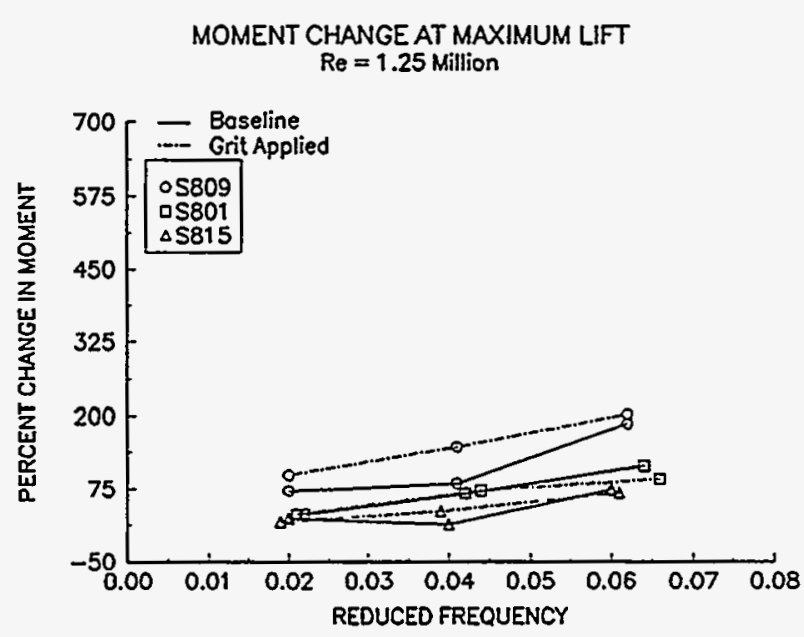

Figure 21. Moment change at maximum lift.

change between the steady state maximum lift and the pitch oscillation maximum lift. The pitching moments at the maximum lift angle of attack were used. The S815 model had the highest lift change when LEGR was applied and the S801 had the least change. The S809 model shows the highest change in pitching moment in the figure, but in comparison with LS(1)-0417MOD, these changes are small. The LS(1)-0417MOD model, although not shown, experienced the highest change in pitching moment from the steady state, up to $670 \%$.

\subsection{6x12 Wind Tunnel Model Testing}

The OSU/AARL $6 \times 12$ Blowdown Wind Tunnel was used for a limited number of tests to determine the feasibility of using this wind tunnel to study some higher Reynolds number data that are out of range of the $3 \times 5$ wind tunnel. The main purpose of the tests were to determine if the facility could provide suitable flow quality at low Mach number and higher Reynolds number, which is desired for large-wind-turbine airfoil testing. To achieve these ends, drag measurements were obtained from a NACA 65A413 airfoil model at 1.5 to 6.0 million Reynolds number. The results showed that, for increasing Reynolds number, the drag coefficient on the airfoil model increased, an unexpected result. This could be because airflow turbulence increases with increasing total pressure, thereby causing the airfoil to transition to a turbulent boundary layer sooner and creating higher drag. This effect has not been observed in the $6 \times 12$ wind tunnel before, but earlier tests were conducted at higher Mach numbers. A summary report of results was delivered to NREL in early August 1994.

\subsection{Project Improvements}

During Phase III, additional changes were made to increase project productivity, such as addressing procedural items and developing new software. 
Written procedures were created or updated for several aspects of this project and have been put into an electronic format so they may be updated and referred to more easily. Other procedures were written for the model tap location and model verification measurement methods and for coordinate preparation. An effort was made to provide written data processing instructions. In addition, check lists were developed for the model preparation and wind tunnel run procedures.

Graduate and Undergraduate Research Assistants still conduct most of the daily work including measurement and validation of the model coordinates and tap locations, preparation of models for testing, installation of models in the wind tunnel, wind tunnel testing, data preparation, and report generation.

Since experimental wind tunnel data are the major products of the OSU/AARL testing, changes are continually being made to improve data processing. The computers purchased in Phase II allowed development and use of a method to more easily plot all the steady state and unsteady wind tunnel data. Implementation of this semi-automatic plotting method has significantly reduced the time required to prepare data for more accurate and timely reports. Additionally, programs have been developed or refined in Phase III to allow for quicker data processing, report generation, and electronic data output. The data reduction routine is currently being examined to determine if it can be streamlined to enable quicker data reduction.

\subsection{Meetings}

OSU/AARL staff participated in the NREL Contractor Review Meeting in October 1993 and presented a paper entitled "Wind Tunnel Evaluation of Airfoils for Horizontal Axis Wind Turbines." OSU/AARL staff also attended the January 1994 ASME/ETCE Wind Energy Symposium in New Orleans and the AWEA Windpower '94 conference in May 1994 where a paper entitled "Unsteady Performance of Wind Turbine Airfoils" was given.

\subsection{Remarks}

Attempts have been made to address project issues and to continually improve project results. Changes that took place in Phase II and Phase III allowed the timely model testing and report generation. For example, the last wind tunnel model examined in Phase III was tested and the data report completed and submitted in a total of two months. Additional modifications applied to data processing improved accuracies and timeliness of the data presented.

In addition to the Principal Investigator, Dr. G.M. Gregorek, and Staff Research Supervisor, Mike Hoffmann, Graduate Research Assistant Robyn Reuss Ramsay and Research Assistants Jolanta M. Janiszewska, Fernando Falasca, and Mònica Angelats i Coll worked on this project. 


\subsection{Future Plans}

In Phase IV, additional wind tunnel tests will be conducted in both the $3 \times 5$ subsonic wind tunnel and the $7 \times 10$ wind tunnel at OSU/AARL. The testing of the $\mathrm{S} 810$ model should be completed by October 1994. The S814 model will be fabricated and then tested in the $3 \times 5$ after the S810 model. The S814 testing is estimated to be completed in November 1994 and the report should be completed by the following month. The aileron model is under development and will be constructed during late November and December 1994. It will be tested in the $7 \times 10$ wind tunnel in January 1995. Subsequently, during Phase IV, at least four more standard models will be tested in the $3 \times 5$ wirid tunnel. The airfoil sections are to be determined in cooperation with the NREL technical monitor.

Also in Phase IV, efforts to incorporate results into analytical models will be initiated. The intent is to use the accumulated aerodynamic results from Phase III as a database for rotor performance prediction codes. Since field data with S809 blades are available, as are unsteady S809 wind tunnel data, those data will be used in an initial code validation effort. The actual computer code(s) used will be determined by mutual agreement between OSU/AARL and NREL participants. 


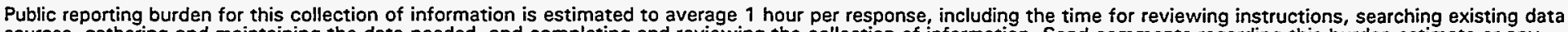

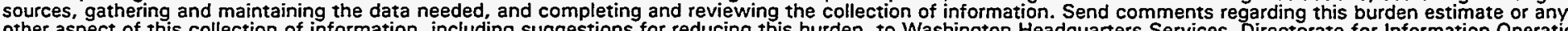

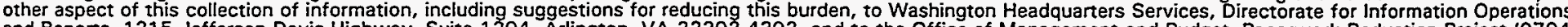

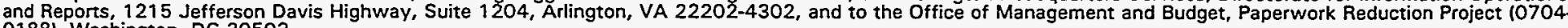
0188 ), Washington, DC 20503
1.
2. REPORT DATE
December 1995

\section{REPORT TYPE AND DATES COVERED} Subcontract Report

\section{TITLE AND SUBTITLE \\ A Study of Pitch Oscillation and Roughness on Airfoils Used for Horizontal Axis Wind Turbines}

6. AUTHOR(S)

G. M. Gregorek, M. J. Hoffmann, R. R. Ramsay, J. M. Janiszewska

5. FUNDING NUMBERS

C:

TA: WE618120

7. PERFORMING ORGANIZATION NAME(S) AND ADDRESS(ES)

Dr. Gerald Gregorek

The Ohio State University

Aero \& Astronautical Research

2300 West Case Road

Columbus, Ohio 43220

(614) 292-5491

9. SPONSORING/MONITORING AGENCY NAME(S) AND ADDRESS(ES)

National Renewable Energy Laboratory

1617 Cole Blvd.

Golden, CO 80401-3393

8. PERFORMING ORGANIZATION REPORT NUMBER

11. SUPPLEMENTARY NOTES

NREL Technical Monitor: C. P. Butterfield

12a. DISTRIBUTION/AVAILABILITY STATEMENT National Technical Information Service U.S. Department of Commerce 5285 Port Royal Road

Springfield, VA 22161 12b. DISTRIBUTION CODE

UC-1211

\section{ABSTRACT (Maximum 200 words)}

Under Subcontract XF-1-11009-3 the Ohio State University Aeronautical and Astronautical Research Laboratory (OSU/AARL) with the National Renewable Energy Laboratory (NREL) developed an extensive database of empirical aerodynamic data. These data will assist in the development of analytical models and in the design of new airfoils for wind turbines. To accomplish the main objective, airfoil models were designed, built and wind tunnel tested with and without model leading edge grit roughness (LEGR). LEGR simulates surface irregularities due to the accumulation of insect debris, ice, and/or the aging process. This report is a summary of project activity for Phase III, which encompasses the time period from September 17, 1993 to September 6, 1994.

14. SUBJECT TERMS

wind energy; horizontal-axis wind turbine; wind tunnel test data; wind turbine airfoil
15. NUMBER OF PAGES

16. PRICE CODE

20. LIMITATION OF ABSTRACT

UL

Standard Form 298 (Rev. 2-89) Prescribed by ANSI Std. Z39-1 